\title{
IP AND RESISTIVITY SURVEY AT THE INEL COLD TEST PIT
}

\author{
William Frangos \\ Earth Sciences Division, Lawrence Berkeley National Lab \\ 1 Cyclotron Road, Berkeley, CA 94720 USA
}

\begin{abstract}
Induced polarization ( $\mathbb{P})$ is a technique for detection of diffuse occurrences of metallic material. The Idaho National Laboratory (INEL) Cold Test Pit (CTP) has been carefully constructed to simulate stored hazardous waste occurrences. IP and resistivity surveys of the CTP show a very strong IP response and a modest resistivity response associated with the simulated waste. Several false positive resistivity anomalies are noted.

2-D inversion of the data accurately determines the lateral limits of the waste zone. The depth of burial indicated is deeper than reported by the construction engineers. Limited depth extent is recognized, in distinction to results from other, resistivity-based, methods, but it also appears too deep. IP holds promise as a method for locating buried waste.
\end{abstract}

\section{INTRODUCTION}

A variety of radioactive and hazardous waste material has been disposed of over the years at the Idaho National Engineering Laboratory (INEL), located in a region of continental flood basalts in the northwestern US. Precise location is unknown for some of the waste dumps. In order to test various methods of non-invasive subsurface waste location techniques, a simulated waste pit has been constructed using safe materials, and designed to resemble old waste pits as closely as possible. This "Cold Test Pit" (CTP), a 12-m wide by 60-m long trench, segmented by transverse berms into cells, has been investigated by a number of workers using several different (see VETEM, 1996). The cell is described as being an "eight-foot [2.4m] waste seam with about four to five feet [1.2-1.5 m] of soil cap." The cap is composed of clay-rich soil from elsewhere in the INEL complex. Host material is local soil overlying resistive Snake River basalt.

While the first reported recognition of what we now call IP was by Conrad Schlumberger (1920), much of its early development sprang from mine warfare research during World War II (Collett, 1990, Grow, 1982). The principal application of IP has been prospecting for disseminated base and precious metal ore deposits, a technology transfer of the wartime research (Bleil, 1948, Bleil, 1953, Collett, 1990). In an early investigation of cultural contamination of domestic water supplies, Angoran et al. (1974) used IP to trace town dumps in Massachusetts. Frangos and Andrezal (1994) reported IP measurements over a landfill and toxic waste pond in Slovakia.

\section{ExPerimental Procedure}

The survey procedure is similar to that for conventional galvanic resistivity surveying, using grounded electrodes with wires between them in any convenient array. In $\mathrm{IP}$, it is particularly important to utilize non-polarizing receiver electrodes. 
A dipole-dipole array was chosen for the work at the CTP because it provides both profiling and sounding information simultaneously. Figure 1 shows the locations of the lines surveyed. Two electrode spacings were employed; all lines were measured with a 5-m spacing, while the northern four lines were surveyed with a $2-\mathrm{m}$ spacing. All data were acquired with an Aquila model A1 phase measuring IP receiver and a battery-powered, currentregulated Auriga transmitter operating at a frequency of $1 \mathrm{~Hz}$. The resistivity data are reported in ohm-meters $(\Omega-m)$ and IP as phase lag in milliradians $(\mathrm{mR})$.

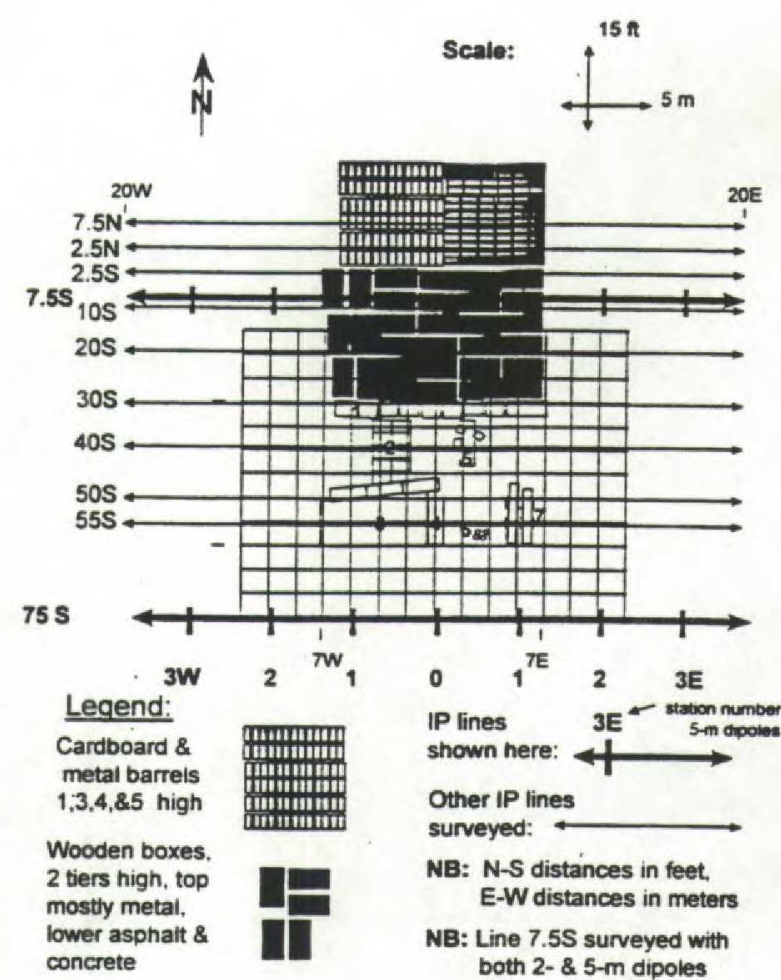

Figure 1: Survey layout at the INEL CTP
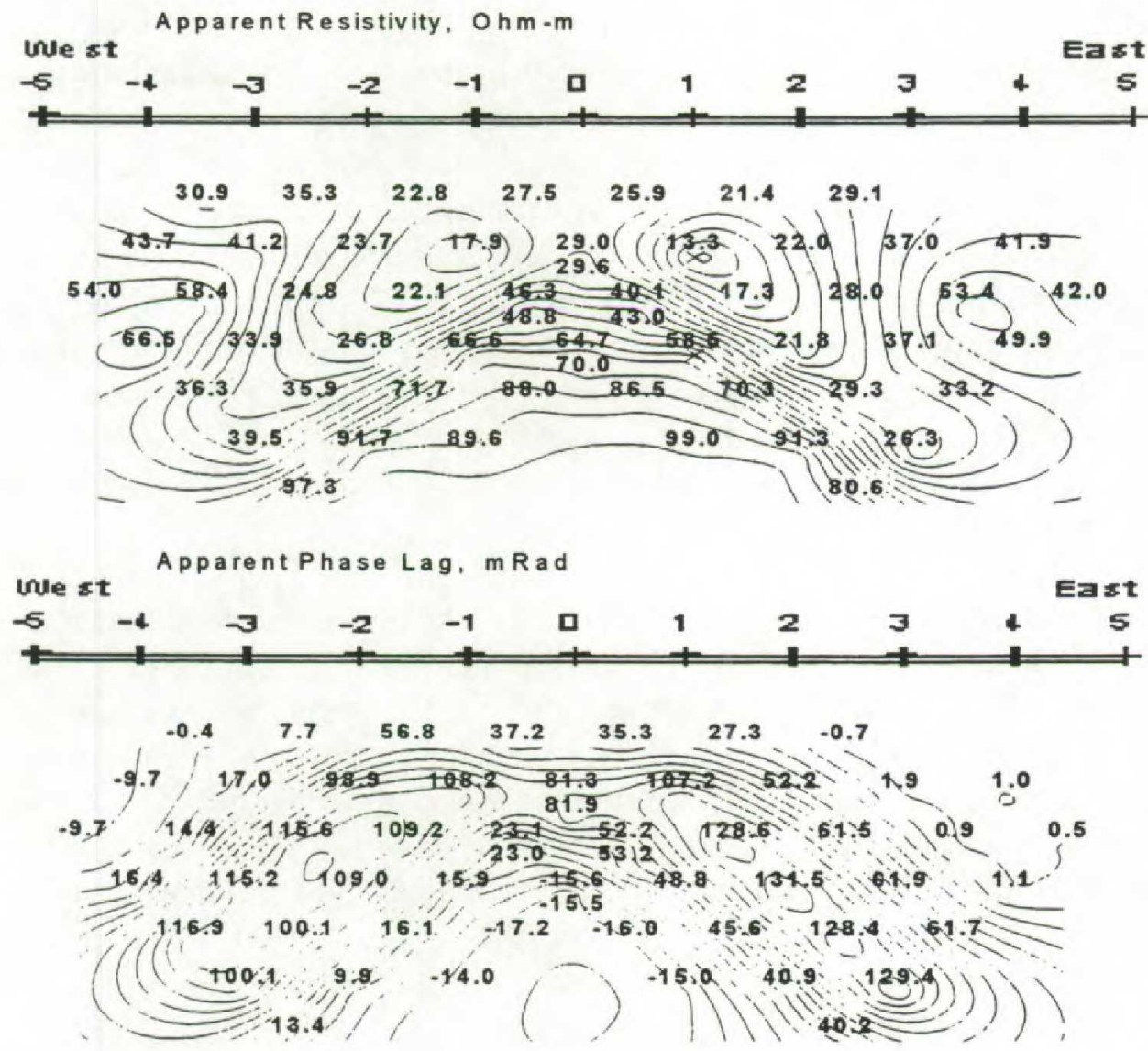

Figure 2: Typical resistivity \& IP results across simulated waste. Line $7.5 \mathrm{~s}, 5-\mathrm{m}$ eter dipoles, $1 \mathrm{~Hz}$ 
Please note that the INEL CTP survey grid is in feet ( 1 foot $=0.305$ meters), with its origin at the southwest corner of the stacked drums, while the IP survey is measured in meters, with distances measured east and west of the center line through the CTP. Station numbers are in dipole units from the transmitter position, e.g., station $3 \mathrm{E}$ is three dipoles east of the center of the line, which is $15 \mathrm{~m}$ for $5-\mathrm{m}$ spaced lines and $6 \mathrm{~m}$ for $2-\mathrm{m}$ lines.

\section{SURVEY RESULTS}

Representative five-meter dipole data from Line $7.5 \mathrm{~S}$ are presented as Figure 2. The background properties were determined in a traverse south of the simulated waste, Line $75 \mathrm{~S}$; resistivity of the fill is about $20-30 \Omega-\mathrm{m}$ and its IP response is $4-5 \mathrm{mR}$. Large resistivity variation occurs within the fill, however; the lowest observed apparent resistivities, 7-10 $\Omega-\mathrm{m}$, were seen on the east end of the background line.

\section{DISCUSSION}

There is a huge IP response from the simulated and relatively small IP effect from the background line. Note that the "pants-leg" pattern in Figure 2, i.e., the two strong anomalous diagonals, is an artifact of the pseudosection plotting convention; the responses originate within a single region near the middle of the line.

A two-dimensional joint inversion of the 2- and 5-m resistivity and IP data of Line $7.5 \mathrm{~S}$ (Figure 2) recovers the conductivity and IP effect distributions shown as Figure 3. The resistivity results show several discontinuous conductive zones, only some of which coincide with the simulated waste (between -7 and $+7 \mathrm{~m}$ ). The IP inversion results, in contrast, show only one responsive zone, well positioned, and, at about 3 meters, a bit deeper than the reported cap thickness of about $1 \frac{1}{2}$ meters. The IP response is somewhat stronger on the
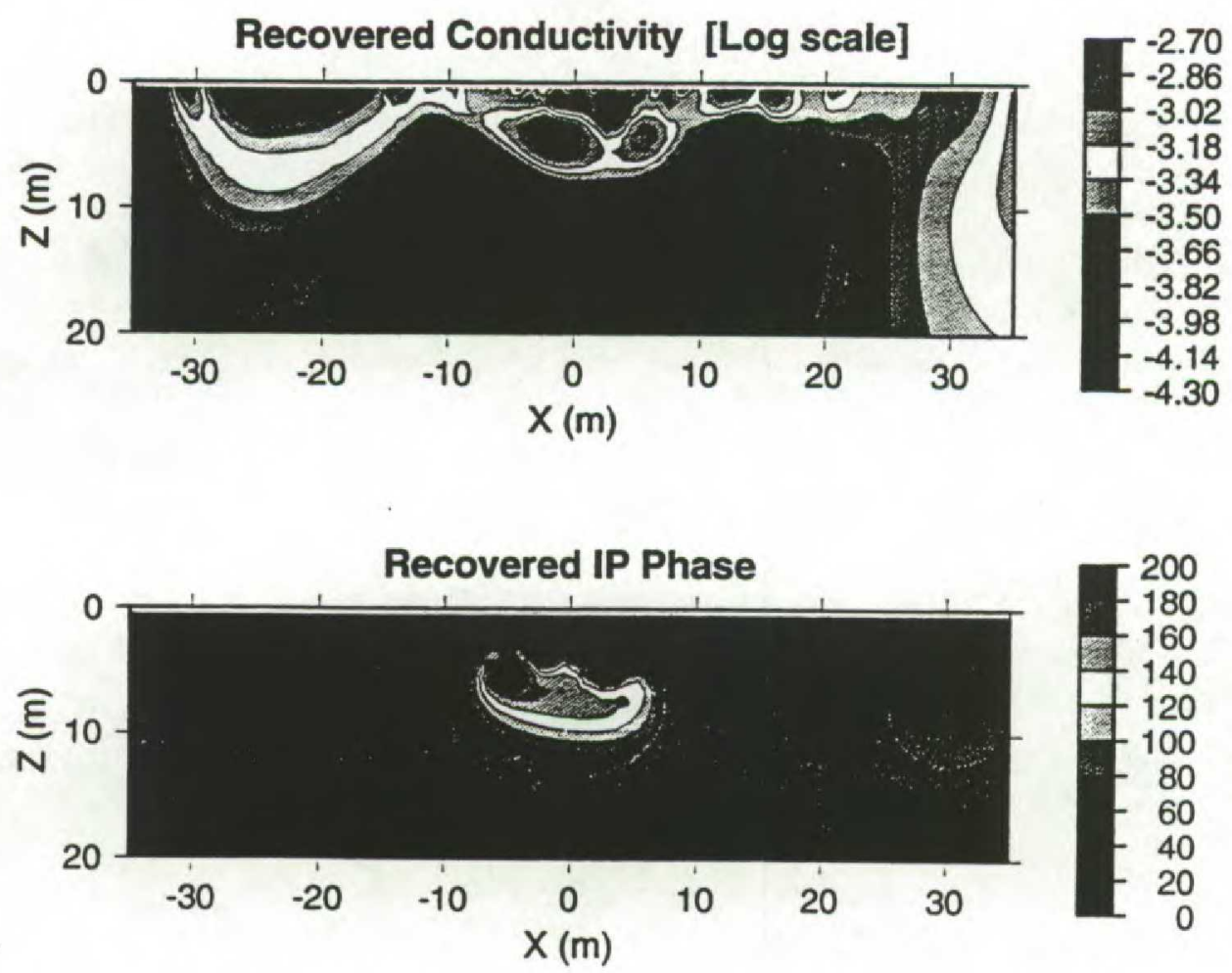

Figure 3: Joint inversion of resistivity and IP data, Line 7.5 S, 2- and 5-meter dipoles 
west end of the responsive body, where the nearby drums are stacked deeper than on the east side. Two possible explanations for the seeming erroneous depth are that 1) the top of the simulated waste lies deeper than the cap thickness, and/or 2) the two-dimensional inversion estimates a three-dimensional body too deep. A bottom is indicated in both the resistivity and $\mathrm{P}$ inversions, and is better resolved by the resistivity.

\section{CONCLUSIONS}

Anomalous responses of both resistivity and IP are noted at the INEL CTP test; apparent resistivity is observed to decrease by a factor of 2 to 3 with respect to background, while apparent IP effect increases by a factor of 50 or 100 . Conductive anomalies are present which are unrelated to the presence of simulated waste.

IP response is large, limited, and spatially correlated with the simulated waste. The edges of the waste zone are well resolved in a two-dimensional inversion, and the top and bottom are detected, though not so well resolved. The interpreted depth to the top of the waste, 3 $4 \mathrm{~m}$, is deeper than the reported cap thickness. To the extent that the CTP is representative of waste at INEL, IP is an excellent tool for its location and delineation.

\section{ACKNOWLEDGMENTS}

The two-dimensional joint inversion was provided by Drs. Yaoguo $\mathrm{Li}$ and Doug Oldenburg of the University of British Columbia. Dr. David Alumbaugh of Sandia National Lab assisted in the data acquisition, as did Mr. Karl Merz of Cornell University and Ms. Suzan Frangos. The work was performed under the auspices of the Very Early Transient Electromagnetics project (VETEM).

\section{REFERENCES}

Angoran, Y., Fitterman, D.V., and Marshall, D.J., 1974, Induced polarization: A geophysical method for locating cultural metallic refuse: Science, vol. 184, no. 4143, pp. $1287-1288$

Bleil, D.F., 1948, Induced polarization: a method of geophysical prospecting: Geophysics, vol. 13, p. 504 (Abstract)

Bleil, D.F., 1953, Induced polarization: a method of geophysical prospecting: Geophysics, vol. 18 , pp. 636-661

Collett, L.S., 1990, History of the induced polarization method in Induced polarization: applications and case histories: Investigations in Geophysics Series, No. 4, SEG, Tulsa

Frangos, W., and Andrezal, T., 1994, IP measurements at contaminant and toxic waste sites in Slovakia; presented at the Sumner IP Workshop, Tucson, 17-20 October

Grow, L.M., 1982, Induced polarization for geophysical exploration: The Leading Edge, vol. 1 , no. 6 , pp. 55-56 and 69-70

Schlumberger, C., 1920, Etude sur la prospection electrique du sous-sol: Gauthier-Villars et Cie., Paris

VETEM, 1996, the VETEM web site at http://vetem.lbl.gov presents data from the EMID project and descriptions of the surveys performed 